\title{
Improving corneal donation rates: a three-phase analysis of professional and patient factors
}

\author{
Authors: Isabel Ng, ${ }^{A}$ Josie Astle, ${ }^{B}$ Emma Tregenna, ${ }^{A}$ Helen Eades ${ }^{B}$ and Sarah Mollart ${ }^{A, C}$
}

\section{Aims}

This three-phase service evaluation project aimed to assess factors that influence corneal donation at the West Suffolk Hospital NHS Foundation Trust (WSH) and St Nicholas Hospice Care (SNHC).

\section{Methods}

Firstly, a questionnaire survey of multidisciplinary team members employed at SNHC was carried out in autumn 2014 to survey their knowledge and experience of corneal donation.

Next, a questionnaire survey was given to patients admitted to SNHC from 25 June to 10 August 2015, unless they: were not eligible for donation, lacked capacity, or had difficulty discussing terminal illness.

Finally, a retrospective study of deaths that occurred in September 2016 at the WSH was carried out. Patients were screened for eligibility for corneal donation based on local guidelines.

\section{Results}

Thirty-seven multidisciplinary staff responded to the questionnaire offered to approximately 100 staff members: $92 \%$ of respondents never or rarely raised the subject of corneal donation with patients or relatives; $76 \%$ had not received any training regarding corneal donation; and $81 \%$ felt they did not know enough about corneal donation to discuss it with patients or relatives. These results were used to inform an education programme for the staff.

During the second phase, 15 of 29 inpatients during that period were eligible for corneal donation. The topic of corneal donation was raised with all eligible inpatients and 14 of them were given a service evaluation questionnaire, with one omission in error. There were 11 respondents. Of these, $55 \%$ had not heard of corneal donation and $100 \%$ were either glad or neutral about being informed about corneal donation. Seventy-three per cent did not find it upsetting to discuss corneal donation, and the remaining $27 \%$ indicated that though they found it upsetting, they would have rather have had the conversation than not. The discussion had an impact on patient plans for donation (Table 1).

During the third phase, 85 deaths occurring at WSH were assessed for eligibility. Of these, 30 were likely eligible for corneal

Authors: ${ }^{A}$ Palliative Care Medicine, West Suffolk Hospital NHS Foundation Trust, UK; ${ }^{B}$ General Practice, West Suffolk Hospital NHS Foundation Trust, UK; C Palliative Care Medicine, St Nicholas Hospice Care, Bury St Edmunds, UK

$\begin{aligned} & \text { Table 1. Patient decisions about cornea donation } \\ & \text { before and after discussion ( } \mathrm{n}=11)\end{aligned}$
$\begin{array}{lll}\text { Decision } & \text { Before discussion } & \text { After discussion } \\ \text { Planning to donate corneas } & 0(0 \%) & 7(64 \%) \\ \text { Not planning to donate } & 7(64 \%) & 1(9 \%) \\ \text { corneas } & & 3(27 \%) \\ \text { Undecided } & 3(27 \%) & 0(0 \%) \\ \text { No answer indicated } & 1(9 \%) & \end{array}$

Table 2. Summary of exclusion criteria met by patients 'not eligible' or only 'potentially eligible'

for corneal donation

$\begin{array}{lll}\text { Exclusion criteria } & \begin{array}{l}\text { Not eligible } \\ (\mathbf{n}=\mathbf{4 5})\end{array} & \begin{array}{l}\text { Potentially } \\ \text { eligible }(\mathbf{n = 1 0 )}\end{array} \\ \begin{array}{l}33(73 \%) \\ \text { Age }\end{array} & \begin{array}{l}0 \%) \\ \text { Degenerative neurological } \\ \text { disorder }\end{array} & 8(16 \%) \\ \begin{array}{l}\text { Haematological malignancy } \\ \text { Blood-borne virus }\end{array} & 4(9 \%) & 0(0 \%) \\ \begin{array}{l}\text { Other (eg history of laser } \\ \text { treatment) }\end{array} & 1(2 \%) & 0(0 \%) \\ & 0(0 \%) & 2(20 \%)\end{array}$

donation, 45 not eligible, and 10 potentially eligible. The reasons for exclusion are shown in Table 2.

\section{Conclusion}

These results highlight factors determining corneal donation rates through an innovative three-phase study. Training and education of staff was identified as lacking by the first phase and addressed through an education programme. The second phase highlighted the willingness of patients to have discussions about corneal donation and the impact of having these discussions. The third phase enabled identification of a target corneal donation rate. Following these interventions, corneal donation rates at SNHC have increased from zero to an average of 50 corneas per year, which is approximately $10 \%$ of the national annual cornea shortage.

\section{Conflict of interest statement}

None declared. 